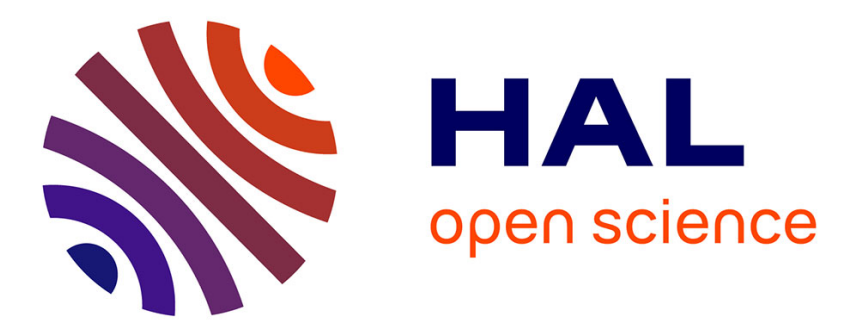

\title{
A tris(benzyltriazolemethyl)amine-based cage as a CuAAC ligand tolerant to exogeneous bulky nucleophiles
} Gege Qiu, Paola Nava, Alexandre Martinez, Cédric Colomban

\section{To cite this version:}

Gege Qiu, Paola Nava, Alexandre Martinez, Cédric Colomban. A tris(benzyltriazolemethyl)aminebased cage as a CuAAC ligand tolerant to exogeneous bulky nucleophiles. Chemical Communications, 2021, 57 (18), pp.2281-2284. 10.1039/D0CC08005E . hal-03175776

\author{
HAL Id: hal-03175776 \\ https://hal.science/hal-03175776
}

Submitted on 3 Dec 2021

HAL is a multi-disciplinary open access archive for the deposit and dissemination of scientific research documents, whether they are published or not. The documents may come from teaching and research institutions in France or abroad, or from public or private research centers.
L'archive ouverte pluridisciplinaire HAL, est destinée au dépôt et à la diffusion de documents scientifiques de niveau recherche, publiés ou non, émanant des établissements d'enseignement et de recherche français ou étrangers, des laboratoires publics ou privés. 


\title{
A Tris(benzyltriazolemethyl)amine-based Cage as CuAAC Ligand Tolerant to Exogeneous Bulky Nucleophiles
}

\author{
Gege Qiu, ${ }^{a}$ Paola Nava, ${ }^{a}$ Alexandre Martinez, ${ }^{\text {*a }}$ and Cédric Colomban*a
}

The archetypal tris(benzyltriazolemethyl)amine (TBTA) ligand was equipped with a bowl-shaped cap in the cage $\mathrm{Hm}$-TBTA. Hm-TBTA accelerate CuAAC reactions without suffering from product inhibition. Furthermore, this shielded ligand efficiently protects the copper center from it deactivation by the $\mathrm{Cu}^{\mathrm{l}}$-chelator glutathione, opening the way to novel approaches for efficient CuAAC reactions in complex media.

The Cu-catalyzed azide-alkyne cycloaddition reaction (CuAAC) is the most popular reaction of the "click chemistry" toolbox. ${ }^{1}$ Due to its high versatility, tolerance, and efficiency under mild conditions, this transformation belongs to the most broadly applicable methods to prepare covalent linkages. ${ }^{2}$ Thus, CuAAC applications range from chemical biology, ${ }^{3}$ medicinal chemistry, ${ }^{4}$ to material science and interlocked structures. ${ }^{5}$ Many efforts have been dedicated to the development of assisting-ligands to improve the reaction efficiency. ${ }^{6}$ In their pioneering work, Sharpless and Fokin report the tris(benzyltriazolemethyl)amine (TBTA) architecture as a remarkable $\mathrm{Cu}^{\prime}$-stabilizing and rate-accelerating ligand. ${ }^{7}$ Since then, TBTA has become the most widely used CUAAC ligand and has been applied in bioconjugation reactions. ${ }^{8}$ Several structural variations of tetradentate triazole-based coordinating structures have been described, ${ }^{6}$ including very recent report of superior water-soluble bioconjugaison CuAAC ligands. ${ }^{9}$ But despite recent progresses, the development of catalysts that remain active in complex mixtures, such as living systems containing biological $\mathrm{Cu}^{\prime}$ ligands, is still needed. ${ }^{10}$ Deactivation of several CuAAC catalysts via coordination of the copper ion by external nucleophiles is indeed proposed to explain their low in-vivo catalytic efficiency. ${ }^{11}$ In this context, providing a second coordination sphere to metal-based catalysts appears as a promising approach due to the crucial benefits offered by confined catalysis in terms of stability and efficiency. ${ }^{12}$ The tris(triazolemethyl)amine structure has been introduced into organic cages and applied in metal-binding in confined space, ${ }^{13}$ or as highly efficient chlorine receptors through $\mathrm{C}-\mathrm{H}$ hydrogen bonding. ${ }^{14}$ However well-defined organic cages based on the TBTA unit have not been evaluated in CuAAC reactions. On this basis, we resonated that the covalent capping of TBTA by another $C_{3}$ symmetrical unit will represent a particularly useful variation of the canonical ligand allowing for the evaluation of the benefits of controlling the second coordination sphere level.
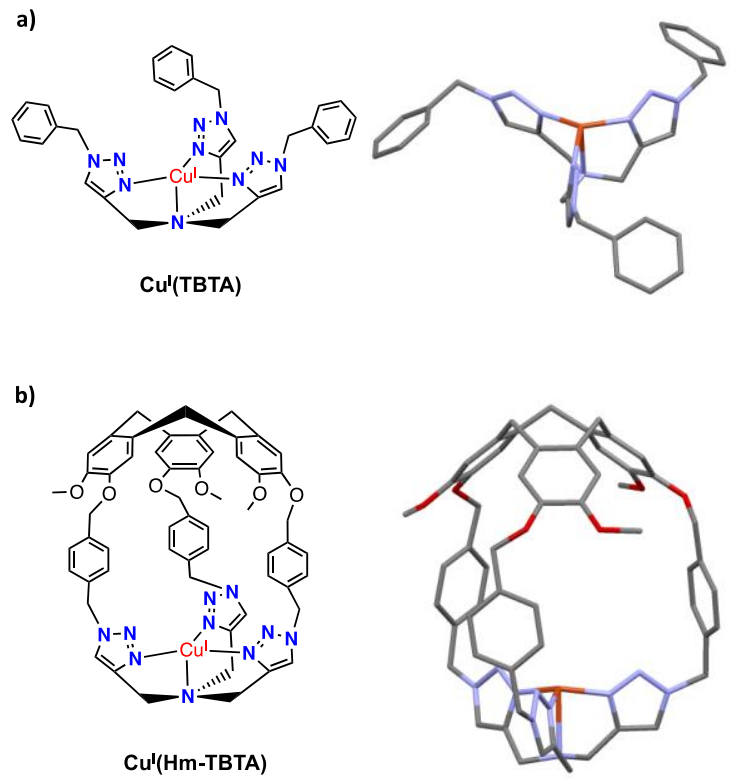

Fig. 1 Schematic representation and DFT-optimized structures (BP86D3/def2-SV $(P)$ ) of (a) the canonical copper complex Cu'(TBTA), and (b) the hemicryptophane complex $\mathbf{C u}^{\prime}(\mathbf{H m}-\mathbf{T B T A})$, target of this study.

In this communication, we present the preparation and evaluation as CuAAC ligand of the novel hemicryptophane $\mathbf{~ H m}$ TBTA that represents an unprecedented organic cage built from the TBTA unit (Fig. 1). We demonstrate the ability of the caged-ligand to coordinate a copper(I) ion at its TBTA moiety and to accelerate the reaction. Furthermore, we compare the performances of TBTA and Hm-TBTA in the presence of two bulky $\mathrm{Cu}$-chelators: the picrate anion $\left(\mathrm{Pic}^{-}\right)$and the Gluthathione biothiol (GSH).

Hemicryptophanes are organic cages constituted of a northern $C_{3}$ symmetrical cyclotryveratrylene (CTV) unit, connected to another tripodal unit. ${ }^{15}$ These structures have been recently reported as a new class of tridimensional ligands allowing for the improvement of bioinspired oxidations involving metalbased catalysts. ${ }^{15,16}$ In this line, we have designed the new hemicryptophane Hm-TBTA where the archetypal TBTA is connected to a CTV unit by three methylene $-\mathrm{CH}_{2}-$ bridges (Fig. 1). Hm-TBTA was obtained in a five-step synthetic procedure (Fig. 2 and Scheme S1, ESI). The $\mathrm{CTV}(\mathrm{OH})_{3}$ unit was derivatized by compound 1 in DMF, using $\mathrm{Cs}_{2} \mathrm{CO}_{3}$ as a base, to yield the CTV derivative 2, which presents three azidomethyl-benzene moieties, in $79 \%$ yield. $\mathrm{Hm}$-TBTA was then obtained following a " $1+1$ " coupling strategy under diluted conditions, that allows for the closure of the cage and the 
formation of the TBTA unit in a single step. The CUAAC reaction between equimolar amount of $\mathbf{2}$ and tripropargylamine, using catalytic quantity of the $\mathrm{CuSO}_{4}$ salt in combination with the TBTA ligand (10 mol\%), and sodium ascorbate NaAsc (reducing agent, 0.5 equiv.) leads to the target cage in $22 \%$ yield. The ${ }^{1} \mathrm{H}$ NMR characterization of $\mathrm{Hm}$-TBTA reveals sharp, identical and well defined signals for the protons belonging to the southern $\mathrm{N}-\mathrm{CH}_{2}-$ link $\left(\mathrm{H}_{\mathrm{a}}\right)$, the TBTA unit $\left(\mathrm{H}_{\mathrm{b}}, \mathrm{H}_{\mathrm{c}, \mathrm{c}^{\prime}}, \mathrm{H}_{\mathrm{d}}\right.$ and $\left.\mathrm{H}_{\mathrm{e}}\right)$, the $-\mathrm{CH}_{2}-$ link $\left(\mathrm{H}_{\mathrm{f}, \mathrm{f}}\right)$, and the CTV unit $\left(\mathrm{H}_{\mathrm{g}}, \mathrm{H}_{\mathrm{h}}, \mathrm{H}_{\mathrm{i}}\right.$ and $\left.\mathrm{H}_{\mathrm{j}, \mathrm{j}^{\prime}}\right)$, attesting an averaged $C_{3}$ symmetrical structure in $\mathrm{CDCl}_{3}$, at room temperature. (Fig. 2 and Fig. S3 and S4, ESI).
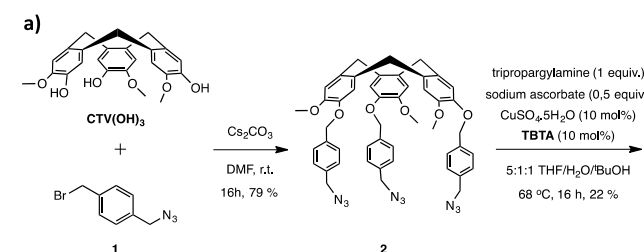
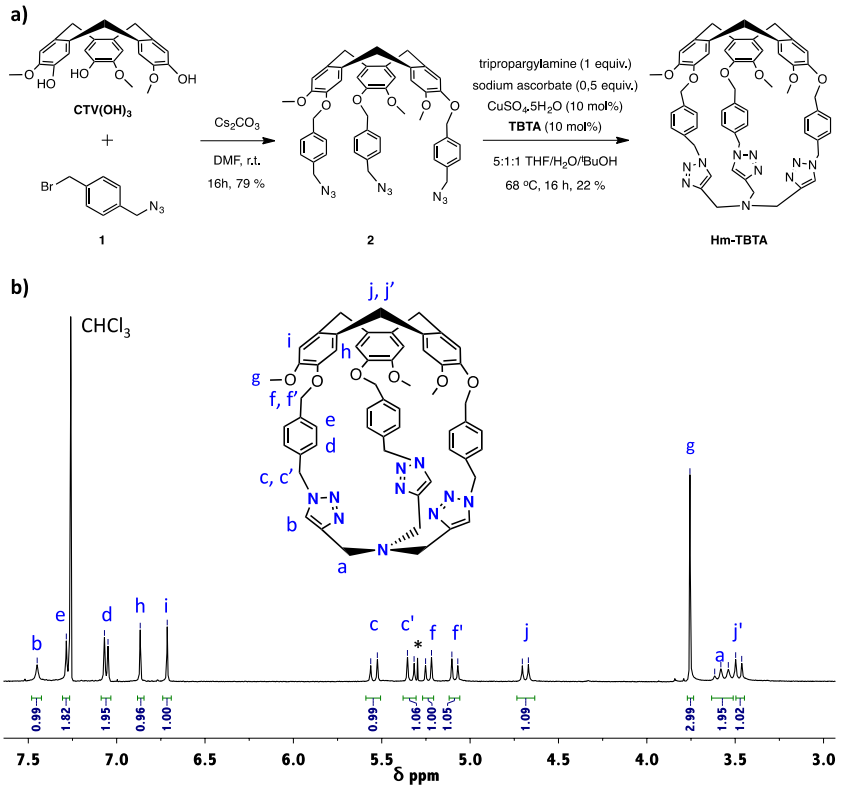

Fig. 2 (a) Synthesis of the hemicryptophane Hm-TBTA along with (b) it ${ }^{1} \mathrm{H}$ NMR spectra $\left(\mathrm{CDCl}_{3}, 400 \mathrm{MHz}\right)$, at $298 \mathrm{~K}\left({ }^{*}=\mathrm{CH}_{2} \mathrm{Cl}_{2}\right)$.

Next, the capability of Hm-TBTA to coordinate a $\mathrm{Cu}(\mathrm{I})$ metalion in its interior was explored. The copper complex $\mathbf{C u}^{\prime}(\mathbf{H m}-$ TBTA)(PF6) was prepared by reacting one equivalent of the $\mathrm{Cu}^{\prime}\left(\mathrm{CH}_{3} \mathrm{CN}\right)_{4}\left(\mathrm{PF}_{6}\right)$ salt in $\mathrm{CH}_{3} \mathrm{CN}$, at room temperature, under inert atmosphere (see $\mathrm{SI}$ ). The formation of the complex was confirmed by High-Resolution Mass Spectrometry (ESI-HRMS) analysis (Fig. S5, ESI). Interestingly, the ${ }^{1} \mathrm{H}$ NMR analysis of $\mathbf{C u}^{\prime}(\mathrm{Hm}-\mathrm{TBTA})\left(\mathbf{P F}_{6}\right)$ reveal a $C_{3}$ symmetrical spectra (on average) in $\mathrm{CD}_{3} \mathrm{CN}$, indicating a retention of the cage symmetry upon copper coordination. Its ${ }^{1} \mathrm{H}$ NMR spectra display identical and well defined signals. Compared to the ${ }^{1} \mathrm{H}-\mathrm{NMR}$ spectrum of the free ligand in $\mathrm{CD}_{3} \mathrm{CN}$, that of $\mathbf{C u}^{\prime}\left(\mathbf{H m}-\mathrm{TBTA}_{\mathbf{A}}\left(\mathbf{P F}_{6}\right)\right.$ displays signals corresponding to the triazole $\left(\mathrm{H}_{\mathrm{b}}\right)$ and the $-\mathrm{CH}_{2}-\mathrm{Ar}\left(\mathrm{H}_{\mathrm{c}, \mathrm{c}^{\prime}}\right)$ moieties that appear shifted and broader (Fig. S9, ESI), in good agreement with a binding of the $\mathrm{Cu}(\mathrm{I})$ ion at the southern coordinating unit. These NMR observations, which reveal that the $C_{3}$ symmetry of $\mathrm{Hm}$-TBTA is retained upon metal coordination at its tris(triazolemethyl)amine unit, strongly suggest that the coordination of the $\mathrm{Cu}^{\prime}$ metal ion occurs with an endohedral functionalization of the copper complex. ${ }^{17}$ The performance of our capped ligand Hm-TBTA was then evaluated and compared with the one of its related open analogue, in a model CuAAC transformation. We have studied the cycloaddition reaction between benzyl azide and phenylacetylene 3 , catalyzed by $1.0 \mathrm{~mol} \%$ of the $\mathrm{Cu}^{\prime}\left(\mathrm{CH}_{3} \mathrm{CN}\right)_{4}\left(\mathrm{PF}_{6}\right)$ metal salt, in the absence of reducing agent, in a $10: 1 \mathrm{CH}_{2} \mathrm{Cl}_{2} / \mathrm{MeOH}$ solvent mixture, at room temperature, under an oxygen-protected atmosphere (see ESI). The yields of the desired product $\mathbf{4}$ have been determined for reactions performed in the presence of $1.0 \mathrm{~mol} \%$ of the tris(triazole)based structures Hm-TBTA or TBTA, as well as in the absence of stabilizing ligand (Table 1, entry 1,2 and 3). For a more rigorous comparison, reaction yields have been compared at a short reaction time of 2 hours, when a third of the maximum yield was obtained in the case of the TBTA ligand (35\% yield, Table 1, entry 3). At longer reaction time (24 h) quantitative yields were obtained for both TBTA and Hm-TBTA (Table 1, entry 4 and 5).

Table 1 Comparison of CUAAC accelerating ligand Hm-TBTA and TBTA. ${ }^{[a]}$

\begin{tabular}{|c|c|c|c|c|c|}
\hline \multirow[b]{2}{*}{ Entry } & $\mathrm{N}_{3}+\equiv$ & 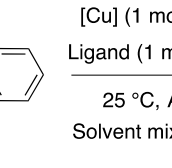 & $\begin{array}{l}\text { I\%) } \\
\text { ol\%) } \\
\text { ture }\end{array}$ & 4 & \\
\hline & $\begin{array}{l}\text { [Cu] source } \\
(1 \mathrm{~mol} \%)\end{array}$ & $\begin{array}{l}\text { Reducing agent } \\
(5 \mathrm{~mol} \%)\end{array}$ & $\begin{array}{l}\text { Ligand } \\
(1 \mathrm{~mol} \%)\end{array}$ & $\begin{array}{l}\text { Time } \\
\text { (h) }\end{array}$ & $\begin{array}{l}\text { Yield }^{[\mathrm{c]}} \\
(\%)\end{array}$ \\
\hline 1 & {$\left[\mathrm{Cu}^{\prime}\left(\mathrm{CH}_{3} \mathrm{CN}\right)_{4}\right] \mathrm{PF}_{6}$} & - & none & 2 & $<1$ \\
\hline 2 & {$\left[\mathrm{Cu}^{\prime}\left(\mathrm{CH}_{3} \mathrm{CN}\right)_{4}\right] \mathrm{PF}_{6}$} & - & Hm-TBTA & 2 & 17 \\
\hline 3 & {$\left[\mathrm{Cu}^{\prime}\left(\mathrm{CH}_{3} \mathrm{CN}\right)_{4}\right] \mathrm{PF}_{6}$} & - & TBTA & 2 & 35 \\
\hline 4 & {$\left[\mathrm{Cu}^{\prime}\left(\mathrm{CH}_{3} \mathrm{CN}\right)_{4}\right] \mathrm{PF}_{6}$} & - & Hm-TBTA & 24 & 99 \\
\hline 5 & {$\left[\mathrm{Cu}^{\prime}\left(\mathrm{CH}_{3} \mathrm{CN}\right)_{4}\right] \mathrm{PF}_{6}$} & - & TBTA & 24 & 99 \\
\hline 6 & {$\left[\mathrm{Cu}^{\prime}\left(\mathrm{CH}_{3} \mathrm{CN}\right)_{4}\right] \mathrm{PF}_{6}$} & - & Hm-TBTA & 0.5 & 6 \\
\hline 7 & {$\left[\mathrm{Cu}^{\prime}\left(\mathrm{CH}_{3} \mathrm{CN}\right)_{4}\right] \mathrm{PF}_{6}$} & - & TBTA & 0.5 & 12 \\
\hline $8^{[0]}$ & $\mathrm{Cu}^{\prime \prime S O} \mathrm{O}_{4}$ & $\mathrm{NaAsc}$ & Hm-TBTA & 2 & 43 \\
\hline $9^{[0]}$ & $\mathrm{Cu} \mathrm{CO}_{4}$ & $\mathrm{NaAsc}$ & TBTA & 2 & 64 \\
\hline $10^{[0]}$ & $\mathrm{Cu}^{\prime \prime} \mathrm{SO}_{4}$ & $\mathrm{NaAsc}$ & Hm-TBTA & 16 & 85 \\
\hline $11^{[0]}$ & $\mathrm{Cu} \mathrm{SO}_{4}$ & $\mathrm{NaAsc}$ & TBTA & 16 & 95 \\
\hline
\end{tabular}

[a] Reaction conditions: benzyl azide (0.2 mmol), phenylacetylene (1.0 equiv.), $\left[\mathrm{Cu}^{\prime}\left(\mathrm{CH}_{3} \mathrm{CN}\right)_{4}\right] \mathrm{PF}_{6}(1 \mathrm{~mol} \%)$, in a $1: 10 \mathrm{MeOH} / \mathrm{CH}_{2} \mathrm{Cl}_{2}$ solvent mixture, at $25^{\circ} \mathrm{C}$, under argon atmosphere. [b] benzyl azide $(0.2 \mathrm{mmol})$, phenylacetylene (1 equiv.), $\mathrm{Cu}^{\prime l} \mathrm{SO}_{4}(1 \mathrm{~mol} \%)$, sodium ascorbate ( $\mathrm{NaAsc}, 5 \mathrm{~mol} \%$ ) in a 2:1:1 $\mathrm{THF} / \mathrm{H}_{2} \mathrm{O} / \mathrm{B} \mathrm{BuOH}$ solvent mixture, at $25^{\circ} \mathrm{C}$. [c] Yields determined by ${ }^{1} \mathrm{H}$ NMR using 2,4-dibromomesitylene as internal standard.

Importantly, after 2 hours, the model CuAAC reaction in the presence of Hm-TBTA (1 mol\%) gave 17\% yield while the ligand-free experiment only produces trace of 4 (Table 1, entry 2 and 1 respectively). Therefore $\mathrm{Hm}$-TBTA clearly acts as an accelerating ligand for CUAAC reaction, allowing for the observation of several turnover numbers without suffering from product inhibition effect. It should be noted that inhibition by a product that end up trapped in the catalyst's tridimentional structure, is a common issue of supramolecular catalysis. ${ }^{18}$ These results therefore highlight the flexible nature of the $\mathbf{H m}$ TBTA ligand that does not become eventually blocked by the triazole product 4 . This flexibility, which also guarantees the access of both substrates to the copper active site, contrasts with other confined Cu'-catalysts. For example, the encapsulation of a $\mathrm{Cu}^{\prime}$-carbene catalyst within a cucurbit[7]uril 
host has been very recently used to fully suppress the CuAAC reaction. ${ }^{19}$ The flexibility of $\mathrm{Hm}$-TBTA has been further demonstrated by extending the substrate scope to hindered phenylacetylenes. Reactions between para (5, 6, 7), meta (8), and ortho-substituted (9) alkynes and benzyl azide, indeed yield the corresponding products $\mathbf{P}_{5-9}$ with quantitative NMR-yields, after $24 \mathrm{~h}$ of reaction time (Fig. 3). The reaction is not suppressed by theses substrates and Hm-TBTA does not end up blocked by the bulky $\mathbf{P}_{5-9}$ products. In addition, competition CuAAC reactions of systems containing two alkynes (at 2 hours reaction time), reveal modest substrate-selectivity improvements in the case of Hm-TBTA (compared to the open TBTA ligand) (See Fig. S12, ESI).

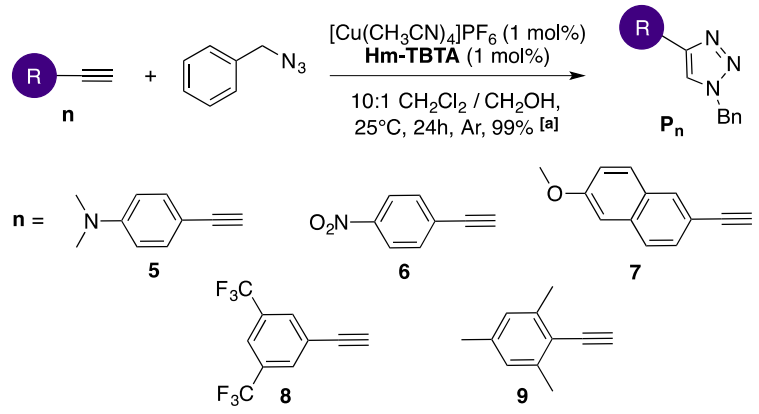

Figure 3. Preparation of triazole products $\mathbf{P}_{\mathrm{n}}$ in quantitative yield using the CuAAC ligand Hm-TBTA. [a] reaction conditions: see table 1.

The direct comparison between Hm-TBTA and its related "uncaged" model reveals a 2 -fold decrease of the catalytic efficiency. Indeed, $17 \%$ and $35 \%$ yields were obtained after 2 hours using respectively Hm-TBTA and TBTA ligands (Table 1 , entry 2 and 3). Comparison of the DFT-optimized structures of the two copper complexes (Fig. 1) clearly shows a widely exposed $\mathrm{Cu}^{\prime}$-center in the case of $\mathrm{Cu}^{\prime}$ (TBTA), while a much more hindered metal core is observed in $\mathbf{C u}^{\prime}(\mathrm{Hm}-\mathrm{TBTA})$. Furthermore, it has been proposed that the TBTA-assisted CuAAC reaction involves a dinuclear copper intermediate allowed by the dissociation of triazole arms. ${ }^{20}$ Therefore, a more difficult formation of such dinuclear complex for the capped ligand might account for it slower catalytic performance. Study of the influence of the Hm-TBTA : $\mathrm{Cu}^{\prime}$ ratio reveal a strong enhancement of the catalytic efficiency upon addition of a second copper ion (Table S1, ESI). Although the existence of a monometallic mechanism could not be excluded, these results strongly suggest that Hm-TBTA is flexible enough to allow a bimetallic mechanism. Interestingly, Hm-TBTA (1 mol\%) was also an effective accelerating ligand for aqueous CuAAC reaction using a $\mathrm{Cu}^{\prime \prime}$ salt $\left(\mathrm{Cu}^{\prime \prime}\left(\mathrm{SO}_{4}\right), 1 \mathrm{~mol} \%\right)$ in combination with a reducing agent (NaAsc, $5 \mathrm{~mol} \%$ ) in a 2:1:1 $\mathrm{THF} / \mathrm{H}_{2} \mathrm{O} / \mathrm{t} \mathrm{BuOH}$ solvent mixture (Table 1 entry 8 ). We then wonder if the steric shield offered by Hm-TBTA could protect the copper catalyst from its inhibition by external bulky nucleophiles. Aiming at establishing a proof of our concept, we first examine the putative shielding effect of Hm-TBTA by studying our model CuAAC reaction in the presence of the potassium picrate salt $\left(\mathrm{K}^{+} \mathrm{Pic}^{-}\right)$. We choose the bulky picrate nucleophile because $(i)$ it can bind to Cu-complexes, ${ }^{21}$ and (ii) it has been previously reported that this anion cannot access the cavity of hemycryptophane cages, due to its large size..22 Interestingly, the data in Fig. 4 revealed that the Hm-TBTAassisted CuAAC reaction did not suffer from deactivation when performed in the presence of up to 70 equivalents of $\mathrm{K}^{+} \mathrm{Pic}^{-}$ compared to the $\mathrm{Cu}^{\prime}$ source. Contrastingly, the catalytic performance of its parent open ligand TBTA was strongly affected by the Pic nucleophile: the yield of triazole product 4 dramatically drop from $35 \%$ (in the absence of external nucleophile), to $17 \%, 9 \%$, and $7 \%$ yields in the presence of respectively 10, 20 and 70 mol\% of $\mathrm{K}^{+} \mathrm{Pic}^{-}$(Fig. 4, and Table S2, ESI).

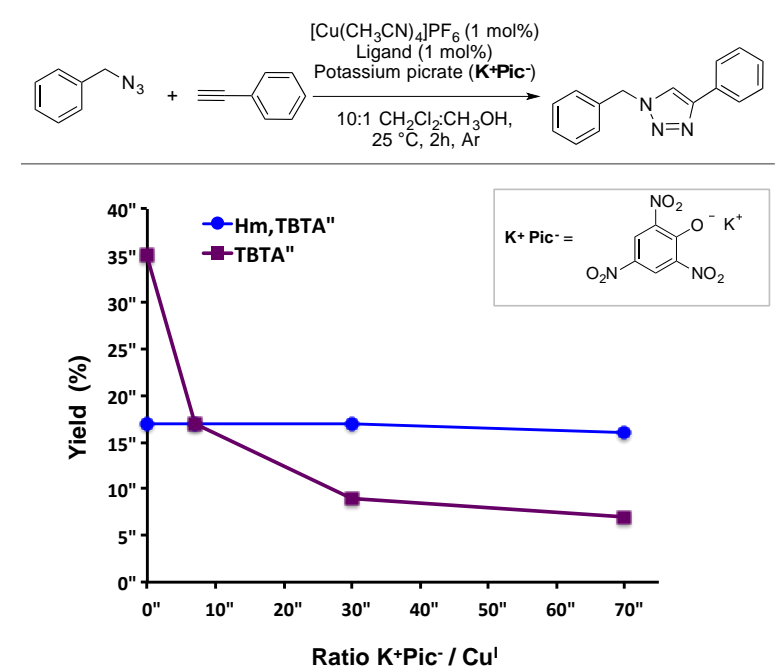

Fig. 4 CuAAC reaction between benzyl azide $(0.2 \mathrm{mM})$ and phenylacetylene (1.0 equiv.), catalyzed by $1.0 \mathrm{~mol} \%$ of $\mathrm{Cu}^{\prime}\left(\mathrm{CH}_{3} \mathrm{CN}\right)_{4}\left(\mathrm{PF}_{6}\right)$, in the presence of $0,10,30$, and $70 \mathrm{~mol} \%$ of potassium picrate $\left(\mathrm{K}^{+} \mathrm{Pic}\right)$, using $1.0 \mathrm{~mol} \%$ of $\mathrm{Hm}$-TBTA (blue circle) or TBTA (purple square), yields determined by ${ }^{1} \mathrm{H}$ NMR.

Clearly, the CTV-capped Hm-TBTA structure offers a powerful steric shield protecting the copper complex from the competitive binding of the bulky picrate anion. Inspired by this observation, we next sought to explore the possibility of using Hm-TBTA to shield the metal ion from its binding by bulky biological $\mathrm{Cu}(\mathrm{I})$ ligands. The glutathione reduced (GSH) thiol was selected as a model biological nucleophile because this tripeptide is particularly abundant in the biological milieu, with concentrations that could range from micromolar to $10 \mathrm{mM},{ }^{10 \mathrm{~b}}$, 22 and its coordination to the copper is considered as the major factor that greatly hampered bioconjugaison reactions. Inhibition of tris(triazolemethyl)amine-based CuAAC catalysts in the presence of $23,{ }^{23}$ and even 2 equivalents of $\mathrm{GSH},{ }^{10 a}$ with respect to copper, have been reported. As expected, when TBTA (1 mol\%) was applied in the model CuAAC reaction, in the presence of GSH (20 mol\%), a marked decrease in efficiency was observed. After 2 hours, the reaction yield dramatically drops from $35 \%$ (in the absence of biothiol), to only $7 \%$ after addition of 20 equivalents of GSH compared to the copper (Table 2). Remarkably, we observed that our CTVcapped ligand was able to efficiently protect the active $\mathrm{Cu}^{\prime}$ ion as the catalytic performance was retained in the presence of 20 mol\% of the sulfur-containing amino acid. After 6 and $24 \mathrm{~h}$ of 
reaction in the presence of GSH (20 mol\%), the transformation accelerated by Hm-TBTA was significantly more efficient than in the case of TBTA with respectively 30 and $99 \%$ yields, while no further formation of product $\mathbf{4}$ was observed for the open ligand (6 - 7\% yields, Table 2). Importantly, isolated yields obtained after $24 \mathrm{~h}$ confirm this remarkable behavior (Table 2 , entry 4 and 8 ). The caged ligand Hm-TBTA therefore provides a powerful steric shield that prevents the competitive binding of bulky exogeneous $\mathrm{Cu}^{\prime}$-ligand, preserving a high catalytic performance even in the presence of 20 equivalents of the notorious CuAAC inhibitor GSH, with respect to the copper.

Table 2 Comparison of TBTA- and Hm-TBTA-assisted CuAAC reactions in the presence of the biological thiol gluthatione (GSH). ${ }^{[a]}$

\begin{tabular}{|c|c|c|c|c|}
\hline & $N_{3}$ & $\begin{array}{r}{\left[\mathrm{Cu}\left(\mathrm{CH}_{3} \mathrm{CN}\right)_{4}\right] \mathrm{PF}_{6}} \\
\text { Ligand (1 molo } \\
\text { Gluthatione (GS } \\
\begin{array}{r}10: 1 \mathrm{CH}_{2} \mathrm{Cl}_{2}: \mathrm{CH}_{2} \\
25^{\circ} \mathrm{C}, \mathrm{Ar}\end{array}\end{array}$ & & \\
\hline Entry & Ligand & Gluthatione (GSH) & $\begin{array}{l}\text { Time } \\
\text { (h) }\end{array}$ & Yield $(\%)^{[b]}$ \\
\hline 1 & TBTA & none & 2 & 35 \\
\hline 2 & TBTA & $20 \mathrm{~mol} \%$ & 2 & 7 \\
\hline 3 & TBTA & $20 \mathrm{~mol} \%$ & 6 & 6 \\
\hline 4 & TBTA & $20 \mathrm{~mol} \%$ & 24 & 7 (traces $\left.{ }^{[c]}\right)$ \\
\hline 5 & Hm-TBTA & none & 2 & 17 \\
\hline 6 & Hm-TBTA & $20 \mathrm{~mol} \%$ & 2 & 15 \\
\hline 7 & Hm-TBTA & $20 \mathrm{~mol} \%$ & 6 & 30 \\
\hline 8 & Hm-TBTA & $20 \mathrm{~mol} \%$ & 24 & $99\left(83^{[c]}\right)$ \\
\hline
\end{tabular}

[a] Reaction conditions: benzyl azide $(0.2 \mathrm{mmol})$, phenylacetylene (1.0 equiv.), $\left.\left[\mathrm{Cu}^{\prime}\left(\mathrm{CH}_{3} \mathrm{CN}\right)_{4}\right] \mathrm{PF}_{6} 1 \mathrm{~mol} \%\right)$, in a $1: 10 \mathrm{MeOH} / \mathrm{CH}_{2} \mathrm{Cl}_{2}$ solvent mixture, at $25^{\circ} \mathrm{C}$, under argon atmosphere, in the presence of $\mathrm{GSH}(20$ mol\%). [b] ${ }^{1} \mathrm{H}$ NMR yields. [c] Isolated yields.

In summary, we described herein the first covalent capping of the canonical CuAAC-ligand TBTA that has been equipped with a CTV unit, providing a steric shield at the second coordination sphere. We demonstrate that the resulting cage $\mathrm{Hm}$-TBTA coordinates a copper metal ion in its interior. Hm-TBTA is a tridimensional CuAAC accelerating-ligand that does not suffer from product inhibition. The Hm-TBTA-assisted transformation is slower than in the case of the parent TBTA. However, we evidence that our CTV-shielded ligand protects the metal ion from its deactivation by external bulky nucleophiles. Indeed, while the catalytic performance of the TBTA ligand was drastically reduced in the presence of bulky $\mathrm{Cu}$ chelators (Pic-, GSH), the Hm-TBTA-assisted CuAAC was not affected. Remarkably, no significant change of the catalytic efficiency was observed even in the presence of 20 equivalents (with respect to the copper) of the notorious biological CuAAC inhibitor gluthatione. We envisioned that our approach could find applications in the field of CuAAC chemistry in complex mixtures. In particular, future work will be devoted to a deeper understanding of the mechanism of such transformation, using caged supporting ligands.

This work was supported by ANR (PRC ANR-19-CE070024-01).

\section{Conflicts of interest}

There are no conflicts to declare. 


\section{Notes and references}

${ }^{1}$ L. Jin, D. R. Tolentino, M. Melaimi, and G. Bertrand, Sci. Adv., 2015, 1, e1500304

2 R. Berg, and B. F. Straub, Beilstein J. Org. Chem., 2013, 9, 2715-2750.

${ }^{3}$ a) C. S. McKay, and M. G. Finn, J. Chem. Biol., 2014, 9, 10751101 ; b) J. Chen, J. Wang, K. Li, Y. Wang, M. Gruebele, A. L. Ferguson, and S. C. Zimmerman, J. Am. Chem. Soc., 2019, 141, 9693-9700.

${ }^{4}$ H. Li, R. Aneja, and I. Chaiken, Molecules, 2013, 18, 97979817.

${ }^{5}$ J. E. M. Lewis, P. D. Beer, S. J. Loeb, and S. M. Goldup, Chem. Soc. Rev., 2017, 46, 2577-2591.

${ }^{6}$ J. E. Hein, and V. V. Fokin, Chem Soc Rev., 2010, 39, 13021315.

7 T. R. Chan, R. Hilgraf, K. B. Sharpless, and V. V. Fokin, Org. Lett., 2004, 6, 2853-2855.

${ }^{8}$ K. E. Beatty, F. Xie, Q. Wang, and D. A. Tirrell, J. Am. Chem. Soc., 2005, 127, 14150-1415.

9 Y.-Y. Guo, B. Zhang, L. Wang, S. Huang, S. Wang, Y. You, G. Zhu, A. Zhu, M. Geng, and L. Li, Chem. Commun., 2020, DOI: $10.1039 / \mathrm{d} 0 \mathrm{cc} 06348 \mathrm{~g}$.

10 a) V. Hong, S. I. Presolski, C. Ma, and M. G. Finn, Angew. Chem. Int. Ed., 2009, 48, 9879 -9883 ; b) Z. Zhu, H. Chen, S. Li, X. Yang, E. Bittner, and C. Cai. Catal. Sci. Technol. 2017, 7 , 2474-2485.

11 T. V. Tran, G. Couture, and L. H. Do, Dalton Trans., 2019, 48, 9751-9758.

12 a) M. Raynal, P. Ballester, A. Vidal-Ferran, and P. W. N. M. van Leeuwen, Chem. Soc. Rev. 2014, 43, 1734-1787, b) M.
Morimoto, S. M. Bierschen, K. T. Xia, R. G. Bergman, K. N. Raymond, and F. Dean Toste, Nat Catal., 2020, DOI :10.1038/s41929-020-00528-3

${ }^{13}$ V. Steinmetz, F. Couty, and O. R. P. David, Chem. Commun., 2009, 343-345.

${ }^{14}$ Y. Liu, W. Zhao, C.-H. Chen, and A. H. Flood, Science 2019, 365, 159-161.

15 D. Zhang, A. Martinez, and J.-P. Dutasta, Chem. Rev. 2017, 117, 4900-4942.

${ }^{16}$ S. A. Ikbal, C. Colomban, D. Zhang, M. Delecluse, T. Brotin, V. Dufaud, J. P. Dutasta, A. B. Sorokin, and A. Martinez, Inorg. Chem. 2019, 58, 7220-7228

17 G. Qiu, C. Colomban, N. Vanthuyne, M. Giorgi, and A. Martinez. Chem. Commun. 2019, 55, 14158-14161.

18 R. J. Hooley, Nat. Chem. 2016, 8, 202-204.

19 T. G. Brevé, M. Filius, C. Araman, M. P. van der Helm, P.-/ Hagedoorn, C. Joo, S. I. van Kasteren, and R. Eelkema, Angew. Chem. Int. Ed. 2020, 59, 9340-9344.

20 (a) V. O. Rodionov, S. I. Presolski, D. Diaz Diaz, V. V. Fokin, and M. G. Finn, J. Am. Chem. Soc. 2007, 129, 1270512712.(b) B. T. Worrell, J. A. Malik, V. V. Fokin, Science, 340, 457-460.

${ }^{21}$ R. Kumar, S. Obrai, A. Kaur, G. Hundal, H. Meehnian, and A.K. Jana, Polyhedron 2013, 56, 55-61.

22 a) O. Perraud, V. Robert, A. Martinez, and J.-P. Dutasta, Chem. Eur. J. 2011, 17, 4177-4182.

${ }^{23}$ S. Li, L. Wang, F. Yu, Z. Zhu, D. Shobaki, H. Chen, M. Wang, J. Wang, G. Qin, U. J. Erasquin, L. Ren, Y. Wang, and C. Cai, Chem. Sci. 2017, 8, 2107-2114. 